\title{
Guidelines for gene nomenclature in ruminants 1991
}

\author{
E Andresen ${ }^{1}, \mathrm{~T} \mathrm{Broad}^{2}$, L Di Stasio ${ }^{3}$, CHS Dolling 4 , D Hill ${ }^{5}$, \\ K Huston ${ }^{6}$, B Larsen ${ }^{7}$, JJ Lauvergne ${ }^{8}$, H Levéziel ${ }^{9}$, X Malher ${ }^{10}$, \\ P Millar ${ }^{11}$, AL Rae ${ }^{12}$, C Renieri ${ }^{13}$, EM Tucker ${ }^{14}$ \\ 1 Department of Animal Science and Animal Health, \\ Division of Animal Genetics, Bülowsvej 13, DK \\ 1870 Frederiksberg $C$, Denmark; \\ ${ }^{2}$ DSIR Grasslands, Palmerston North, New Zealand; \\ ${ }^{3}$ Department of Animal Science, Via Genova 6, 10126 Turin, Italy; \\ 4 Box 74, McLaren Vale, SA 5171, Australia; \\ ${ }^{5}$ Department of Biochemistry, University of Otago, \\ Box 56, Dunedin, New Zealand; \\ ${ }^{6} 1689$ Arthur Dr, Wooster, OH 44691, USA; \\ 7 National Institute of Animal Science, \\ Department of Animal Physiology and Biochemistry, \\ PO Box 39, DK 8830 Tjele, Denmark; \\ 8 Department of Animal Genetics, Factorial Genetics, \\ INRA CRJ, 78352 Jouy-en-Josas Cedex, France; \\ 9 Department of Animal Genetics, Biochemical Genetics, \\ INRA CRJ, 78352 Jouy-en-Josas Cedex, France; \\ ${ }^{10}$ Animal Production, National Veterinary School, \\ CP 3013, 44087 Nantes Cedex 03, France; \\ 11 Britbreed Ltd, 12A Riselaw Cr, Edinburgh 10, UK; \\ 12 16, Wallace Place, Palmerston North, New Zealand; \\ 13 Institute of Animal Production, Faculty of Veterinary Medicine, \\ Via San Costanzo 4, 06100 Perugia, Italy; \\ 14 AFRC, Institute of Animal Physiology and Genetics Research, \\ Baraham, Cambridge CB2 $4 A T, U K$
}

(Received 22 July 1991; accepted 7 August 1991)

Summary - The set of proposed guidelines for gene nomenclature in sheep (Ovis aries L) and goats (Capra hircus L) which had been drawn up during the 1987 COGNOSAG Workshop at Gontard/Manosque, France, was revised by committees during the 1988 and 1989 COGNOSAG Workshops at Gontard/Manosque, France, and Eugene, Oregon, USA. 
This set has been revised in July 1991, at a workshop at Gontard/Manosque, France, to accommodate all ruminants and to facilitate the development of a comparative genome nomenclature.

cattle / goat / sheep / gene nomenclature

Résumé - Nomenclature des gènes des ruminants 1991. Les directives pour la nomenclature des gènes du mouton (Ovis aries $L$ ) et de la chèvre (Capra hircus $L$ ) élaborées au cours de l'Atelier du COGOVICA tenu à Gontard/Manosque en juillet 1987 ont été révisées lors des Ateliers du COGOVICA de juillet 1988 (Manosque) et de juin 1989 (Eugene, Orégon, Etats-Unis). Ces directives ont été revues en juillet 1991 au cours d'un Atelier du COGOVICA organisé à Gontard/Manosque en juillet 1991, de manière à être applicables à tous les ruminants et afin de faciliter les progrès de la nomenclature comparée de leur génome.

bovin / chèvre / ovin / nomenclature génétique

\section{INTRODUCTION}

The guidelines from the present workshop are based on earlier proposals from COGNOSAG Workshop at Gontard/Manosque, July 1986 (Lauvergne and Searle, 1988), Manosque, July 1987 (Alexieva et al, 1989), Gontard/Manosque, July 1988 and Eugene, June 1989 (Alexieva et al, 1990). The guidelines have been enlarged to include all ruminants and comparative genome nomenclature.

\section{LOCUS}

\section{The locus name}

\section{Choice of name}

The name in English should be brief and either convey as accurately as possible the character affected by alleles segregating at the locus or reflect the effect or function by which the locus is recognized. The name may indicate a morphological or disease character (ear length, for example), a body system or body function, or a biochemical property or nucleotide sequence.

Should several body parts be affected by an allele, the locus would be named after the part in which expression occurs most frequently.

As far as possible, the principle of interspecific homology will be applied to loci detected by biochemical, serological, or nucleotide methods as well as to loci with visible effects.

The use of single letters as names for loci or alleles will be avoided in the future.

For purposes of alphabetic listing, all Greek symbols used in the past should be replaced by Latin letters, and placed after the name. Example : $\beta$ Haemoglobin becomes Haemoglobin Beta. 
If a newly described locus has the same or similar effect to one already named, but no proof of their identity has been obtained, then it may be named in English according to the breed, location, or population of origin.

\section{Printing the name}

The locus name will be in Latin characters or a combination of Latin characters and Arabic numerals. The use of italics is optional.

In order to distinguish the locus name from an allele which may be identically written, the initial letter of the locus name will be capitalised.

If the locus name is of 2 or 3 words, each word will begin with a capital latin character. Examples : Agouti; Ear Length; Fecundity Java, Haemoglobin Beta. Agouti, Ear Length; Fecundity Java; Haemoglobin Beta.

\section{The locus symbol}

\section{Choice of the symbol}

For newly reported loci, special care should be exercised in selecting an appropriate symbol to avoid duplication and confusion with existing nomenclature. Every effort should be made to ensure that the symbols selected should conform to those in current usage for homologous loci.

The locus symbol will consist of 1 to 5 italicised Latin letters or a combination of letters and Arabic numerals.

The initial character will always be a capital Latin character which, if possible, will be the initial letter of the name of the locus to facilitate alphabetical listing.

For loci other than those for coat colour and visible traits, upper case Latin letters only, or upper case letters combined with Arabic numerals must be used.

If the locus name is of 2 or 3 words, and the initial letters are used in the locus symbol, then these letters will be in Latin capitals.

All characters in a locus symbol should be written on the same line; no superscripts or subscripts; no Roman numerals or Greek letters may be used.

Where appropriate, the symbol should indicate the biochemical property or nucleotide sequence.

The rules of mammalian interspecific homology already used in the choice of the name of the locus will be applied to the choice of the symbol.

The designation of prefixes denoting mammalian species of origin was considered but no formal proposals for these are made here.

\section{Printing the symbol}

The locus symbol will be in italics if possible or underlined if not in italics.

Locus symbols need not be italicised in data bases. Example : the symbol of the Agouti locus : $A$ or $\mathrm{A}$. 


\section{ALLELES}

\section{Allele name}

\section{Choice of the name}

Alleles, particularly for coat colour and visible traits, should be given brief names chosen to convey as accurately as possible the variation caused by the allele.

Alleles at other loci if not given names must be given symbols as described in the Allele symbol section.

\section{Printing the name}

The allele name will be in italics, or underlined if not in italics. In order to distinguish the allele name from the locus name which in some cases may be the same, the initial letter of the allele name will always be lower case. This does not apply when a symbol is used instead of an allele name. Examples : the allele for polled condition at the Horns locus : polled or polled, an allele at the Haemoglobin Beta locus : $B$ or $\underline{\mathrm{B}}$.

\section{Allele symbol}

\section{Choice of symbol}

The allele symbol will consist of a maximum of 4 characters (Latin letters or Arabic numerals).

As far as possible the allele symbol will be an abbreviation of the allele name and start with the same letter. In the loci detected by biochemical, serological or nucleotide methods, the allele name and symbol may be identical.

Greek letters and Roman numerals must not be used.

The symbol + can be used alone for identification of the standard allele ("wild type") for alleles having visible effects. Neither + nor - symbols may be used in the alleles detected by biochemical, serological or nucleotide methods.

Alleles known to be recessive should have lower case letters only. All other alleles should have an upper case initial letter with the rest being lower case.

Internationally accepted designations for cell surface antigens, including erythrocyte and lymphocyte antigens, are not at present included in these guidelines.

\section{Printing the symbol}

The allele symbol is always written with the locus symbol and may be written as a superscript following the locus symbol or an asterisk may be introduced between the locus and allele symbols. The allele symbol should be printed adjacent to the locus symbol.

The allele symbol will be in italics if possible and underlined if not in italics.

Allele symbols need not be italicised in data bases. Examples : the recessive allele hornless at the Horns locus in sheep will be printed : 
in italics, $H o^{h 1}$ or $H o * h 1$

underlined, $\mathrm{Ho}^{\mathrm{h} 1}$ or $\mathrm{Ho} * \mathrm{~h} 1$.

The dominant allele polled will have the symbol :

in italics, $\mathrm{Ho}^{\mathrm{P}}$ or $\mathrm{Ho} * \mathrm{P}$

underlined, $\underline{\mathrm{Ho}_{\mathrm{O}}^{\mathrm{P}}}$ or $\underline{\mathrm{Ho} * \mathrm{P}}$.

\section{GENOTYPE TERMINOLOGY}

- The genotype of an individual should be shown by printing the relevant locus and allelic symbols for the 2 homologous chromosomes concerned, separated by a slash, eg, $\mathrm{Ho}^{P} / \mathrm{Ho}^{P}$ or $\mathrm{Ho}^{\mathrm{P}} / \mathrm{Ho}^{\mathrm{P}}$.

- Unlinked loci should be separated by semicolons.

- Linked or syntenic loci should be separated by a space and listed in alphabetical order when gene order and phase are not known.

- For X-linked traits, the hemizygous case should be designated by /Y from the locus and allele symbol, eg, FecX $* \mathrm{I} / \mathrm{Y}$.

- The Y-linked traits should be designated by / $\mathrm{X}$ from the locus and allele symbol.

\section{PHENOTYPE TERMINOLOGY}

The phenotype symbol should have the same characters as genotypic and allelic symbols. The difference is that the characters will not be underlined or in italics and will be written adjacent to each other but without any asterisk. Square brackets [ ] may also be used in phenotypic terminology.

A space should separate locus characters and allele characters, eg the genotype $\mathrm{Ho}^{\mathrm{P}} / \mathrm{Ho}^{+}$is equivalent to phenotype Ho P.

\section{RECOMMENDATION}

COGNOSAG recommends that these guidelines should be used in the naming of loci and alleles discovered in the future.

\section{REFERENCES}

Alexieva SA, Denis B, Dolling CHS, Lauvergne JJ, Lundie RS, Millar P, Rae AL, Renicri C, Sponenberg DP, Tucker EM (1989) Gene nomenclature in sheep and goats 1987. In: Standardized Genetic Nomenclature for Sheep and Goats 1987. COGNOSAD Workshop 1987 (Lauvergne JJ ed) Bureau des Ressources Génétiques, Paris, France, 17-21

Alexieva SA, Aliev GA, Bourzat D, Denis B, Dolling CHS, Lauvergne JJ, Lundie RS, Malher X, Millar P, Rachkovsky ML, Rae AL, Renieri C, Sponenberg DP, Tucker EM (1990) Gene nomenclature in sheep and goats 1989. In: Loci for Coat Colour of Sheep and Goats 1989. COGNOSAG Worshops 1988 and 1989 (Lauvergne JJ, ed) COGOVICA/COGNOSAG, Clamart, France, 3-7 
Lauvergne JJ, Searle AG (1988) Proposed rules for genic nomenclature in sheep and goats. In: Standardized Genetic Nomenclature for Sheep and Goats 1986. COGNOSAG Workshop 1986 (Lauvergne JJ, ed) Bureau des Ressources Génétiques, Paris, France, 107-110 